\title{
MYCOPLASMA AND HOST INTERACTION: IN VITRO GENE EXPRESSION MODULATION IN MYCOPLASMA SYNOVIAE AND INFECTED CHICKEN CHONDROCYTES
}

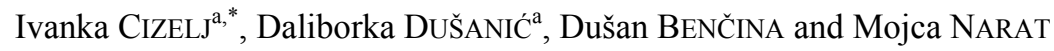 \\ ${ }^{1}$ Department of Animal Science, Biotechnical Faculty, University of Ljubljana, \\ Groblje 3, SI-1230 Domžale, Slovenia
}

(Received 28 July 2015; accepted 28 October 2015)

\begin{abstract}
The complex interplay between Mycoplasma synoviae and chicken chondrocytes $(\mathrm{CCH})$, which come into direct contact during infectious synovitis, has been examined at the level of gene expression. Our previous studies demonstrated a significant influence of $M$. synoviae on the level of $\mathrm{CCH}$ gene expression. Here, we show for the first time that in vitro co-cultivation of $M$. synoviae and $\mathrm{CCH}$ also induces upregulation of gene expression in this mycoplasma. We observed significantly increased expression of genes important for $M$. synoviae pathogenicity, including cysteine protease cys $P$, neuraminidase nan $H$, haemagglutinin $v \operatorname{lh} A$, and the putative nuclease MS53_0284. Moreover, the pattern of gene expression was dependent on the infection environment. In $\mathrm{CCH}$, significant changes in the expression of genes encoding catabolic enzymes of the cartilage extracellular matrix (cathepsins B, K and L, aggrecanase ADAM10, and matrix metalloproteinase MMP2) were demonstrated. Infection of $\mathrm{CCH}$ with $M$. synoviae also elevated the expression of the gene encoding peptidyl arginine deiminase, type III (PADI3), which is responsible for the post-translational citrullination of proteins.
\end{abstract}

Key words: Mycoplasma synoviae, chicken chondrocytes, gene expression, pathogenicity, enzymes

Mycoplasmas are the smallest self-replicating obligatory parasitic bacteria yet discovered, which have a specific cell membrane structure and exhibit an extreme reduction in genome size (Razin et al., 1998). Until recently, it was thought that mycoplasmas regulated gene expression independently of environmental signals, rather than sensing and responding to them, and that their major survival strategy depended on genetic mechanisms of random antigenic variation (Razin et al., 1998). However, Cecchini et al. (2007) showed that Mycoplasma gallisepticum responded to exposure to eukaryotic cells with transcriptional regulation, while Hallamaa et al. (2008) provided evidence of transcriptional regulation of

\footnotetext{
${ }^{\mathrm{a}}$ These two authors contributed equally to the study

*Corresponding author; E-mail: ivanka.cizelj@bf.uni-lj.si; Phone: 00386 (1) 3203-890; Fax: 00386 (1) 7241-005
} 
M. pneumoniae lipoprotein genes in response to in vitro contact with human epithelial cells.

Mycoplasma synoviae colonises the upper respiratory tract of poultry where it causes subclinical infection, while the more invasive strains can cause systemic infection and arthritis (Lockaby et al., 1998; Narat et al., 1998). This phenotype of mycoplasma synthesises variable lipoprotein haemagglutinin VlhA, immunodominant variably expressed membrane lipoproteins that play an important role in binding to the host cell receptors, enabling the colonisation of host tissues. Experimental infection of chickens with M. synoviae has been found to thin the articular cartilage (Kerr and Olson, 1970) while Dušanić et al. (2012) showed that $M$. synoviae infection induces the expression of genes involved in apoptosis in chicken chondrocytes $(\mathrm{CCH})$. In previous studies we identified two $M$. synoviae proteins that can modify chicken proteins: cysteine protease CysP, which cleaves chicken IgG into $\mathrm{Fab}$ and $\mathrm{Fc}$ fragments, and neuraminidase $\mathrm{NanH}$, which desialylates chicken IgG and tracheal mucus glycoproteins in vitro (Berčič et al., 2011; Cizelj et al., 2011). The genome of M. synoviae contains two genes that encode nucleases (MS53_0284 and MS53_0110), although the respective proteins have yet to be reported (Vasconcelos et al., 2005). Meanwhile, it has recently been postulated that autoimmunity, cartilage degradation and chondrocyte degeneration are correlated with the presence of cathepsins B, K and L, aggrecanases and metalloproteinases (Goldring and Marcu, 2009).

The aim of the present study was to investigate whether environmental factors, such as host cell cytoplasm as well as surface and soluble factors from $\mathrm{CCH}$, influence $M$. synoviae gene expression.

\section{Materials and methods}

\section{Cultivation of chicken chondrocytes}

Chicken chondrocytes $(\mathrm{CCH})$ were isolated from hyaline cartilage as described previously (Dušanić et al., 2009) and cultured in Dulbecco's modified Eagle's medium (DMEM, Sigma-Aldrich) supplemented with $7.5 \%$ fetal bovine serum (FBS, Sigma-Aldrich) and 2.5\% chicken serum (Sigma-Aldrich). Cells were cultured at $37{ }^{\circ} \mathrm{C}$ in an incubator with $5 \% \mathrm{CO}_{2}$ atmosphere. The chicken hyaline cartilage tissue was obtained from chickens in strict accordance with the recommendations of the Guide for the Care and Use of Laboratory Animals (National Institutes of Health, Bethesda, MD, USA). The protocol was approved by the Administration of the Republic of Slovenia for Food Safety, Veterinary Sector and Plant Protection (Permit Number: 34401-27/2012/11). 
Cultivation of Mycoplasma synoviae

Cultures of M. synoviae type strain WVU 1853 (Morrow et al., 1990) were cultured in modified Frey's medium at $38^{\circ} \mathrm{C}$ temperature as described previously (Dušanić et al., 2009). Approximately 20 in vitro passages were performed prior to culture, for which M. synoviae in logarithmic growth phase was used for $\mathrm{CCH}$ infection. The number of colony forming units (CFU) was determined by the standard procedure (Rodwell and Whitcomb, 1983).

\section{Experimental design}

$\mathrm{CCH}$ were seeded at $5 \times 10^{5}$ cells per T25 vented tissue-culture flask (Greiner Bio One) and incubated overnight at $37{ }^{\circ} \mathrm{C}$ in $5 \% \mathrm{CO}_{2}$. Based upon the results of our previous studies (Dušanić et al., 2009, 2012), M. synoviae broth culture (MS0) in logarithmic growth phase was used to infect $\mathrm{CCH}$ at a ratio of $50 \mathrm{M}$. synoviae $\mathrm{CFU}$ per $\mathrm{CCH}$. After 24,48 and $72 \mathrm{~h}$ of incubation at $37^{\circ} \mathrm{C}$ in $5 \% \mathrm{CO}_{2}$, culture supernatants were collected and $\mathrm{CCH}$ were sampled by trypsinisation. After washing in sterile phosphate-buffered saline, supernates were combined with the corresponding culture supernatant. In this way two sets of samples were obtained: (i) a pellet containing $\mathrm{CCH}$ and $M$. synoviae attached to or invaded into $\mathrm{CCH}$ (MS-cch24, MS-cch48, MS-cch72), and (ii) supernatants with unattached M. synoviae (MS-sup24, MS-sup48 and MS-sup72), which were further centrifuged to obtain a pellet of bacteria (Table 1). As controls, M. synoviae broth culture used for infection of $\mathrm{CCH}(\mathrm{MS} 0)$ and $\mathrm{CCH}$ culture after 24, 48 or $72 \mathrm{~h}$ of incubation (CTRL24, CTRL48 and CTRL72) were used. Total RNA from all samples was isolated using RNeasy Mini Kit (Qiagen $\mathrm{GmbH}$, Germany) and stored at $-80^{\circ} \mathrm{C}$. RNA was purified from residual DNA with RNase-free DNase I (Fermentas, Germany) and $1 \mu \mathrm{g}$ of total RNA was transcribed to cDNA using a High-Capacity cDNA Reverse Transcription Kit with RNAse Inhibitor (Applied Biosystems, USA), according to the manufacturer's instructions.

\section{Gene expression analysis in $\mathrm{M}$. synoviae}

RT-qPCR analysis was performed following a previously described protocol (Dušanić et al., 2012). Briefly, $20 \mu \mathrm{L}$ mixtures were made, containing $10 \mu \mathrm{L}$ of Power SYBR Green PCR Master Mix (Applied Biosystems, USA), $5 \mu \mathrm{M}$ of each primer (Integrated DNA Technologies, Belgium), $8 \mu \mathrm{L}$ of DEPC-treated water (Qiagen $\mathrm{GmbH}$, Germany), and $1 \mu \mathrm{L}$ of cDNA. Stratagene Mx3000P (Agilent Technologies - Stratagene, USA) was used to perform RT-qPCR reactions and the manufacturer's MxPro software for analysis of amplification and dissociation plots. Gene expression values of MS broth culture (MS0) were used for gene expression calibration. Appropriate controls (no template and no reverse transcription control) were performed in each run. Due to the ability of $M$. synoviae to attach to and invade $\mathrm{CCH}$ (Dušanić et al., 2009), cDNA templates transcribed from 
MS0, MS-sup24, MS-sup48 and MS-sup72 were used along with samples of infected $\mathrm{CCH}$ in which RNA was expected to be produced from Mycoplasma cells that have invaded or been attached to $\mathrm{CCH}$ cells (MS-cch24, MS-cch48, MScch72) (Table 1). Gene expression was tested for four genes (Table 2). The genes encoding proteins involved in $M$. synoviae pathogenicity were included in the gene expression analysis (Berčič et al., 2011; Cizelj et al., 2011). Genes tufA, rsuA and $\operatorname{gid} B$ were used as reference genes based on the stability of their expression during our studies. Prior to use, primer pairs were checked for specificity in silico using NCBI Primer BLAST. Primer efficiency was checked for each primer pair using dilutions of cDNA combined from all experimental conditions and time points.

Gene expression analysis in $\mathrm{M}$. synoviae-infected $\mathrm{CCH}$

RT-qPCR analysis was performed as described for gene expression analysis in M. synoviae. Briefly, gene expression was assayed for six genes (Table 3). The expression of genes RPL13, TBP and HPRT1 did not vary over the course of the experiment and therefore these genes were used as $\mathrm{CCH}$ reference genes. Gene expression values of non-infected $\mathrm{CCH}$ were used for gene expression calibration.

\section{Statistical analysis of gene expression data}

Three independent experiments were performed to collect RNA for RTqPCR. Relative gene expression was assayed for each experiment and experimental condition separately. Three repeats of each RT-qPCR reaction were performed. Normalized relative quantities were obtained using the efficiency corrected $2^{-\Delta \Delta \mathrm{Cq}}$ method (Pfaffl, 2001). Statistical significance between samples from different experimental groups was determined using the unpaired Student's $t$-test $(\mathrm{P}<0.05)$.

\section{Results}

\section{Infection of CCH-induced gene expression in $\mathrm{M}$. synoviae}

Analysis of M. synoviae gene expression revealed three different profiles. The gene expression profile of attached and invaded M. synoviae (MS-cch) differed from that of $M$. synoviae collected from infected $\mathrm{CCH}$ culture supernatant (MS-sup), and from that of the control (MS0) (Fig. 1). The M. synoviae cells that infected $\mathrm{CCH}$ (attached on or invaded into $\mathrm{CCH}$ ) reached a peak of expression of MSPA mRNA at $48 \mathrm{~h}$ after infection (MS-cch48) (11.9-fold, $\mathrm{P}<0.0001)$ and remained elevated after $72 \mathrm{~h}$ (MS-cch72) (4.4-fold, $\mathrm{P}<0.0004)$ compared to expression of MSPA mRNA in MS0. We observed a significant increase (5.6-fold; 


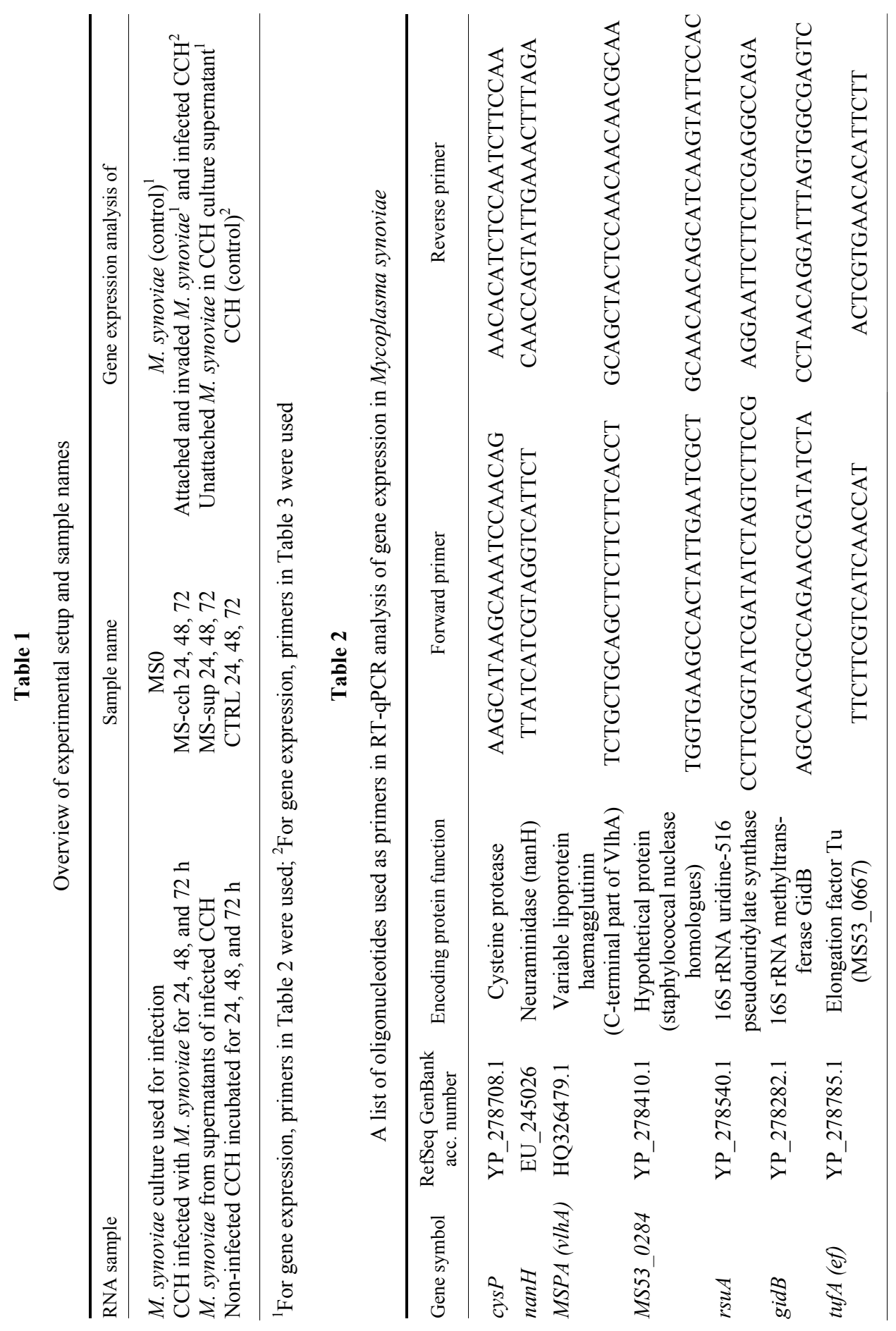




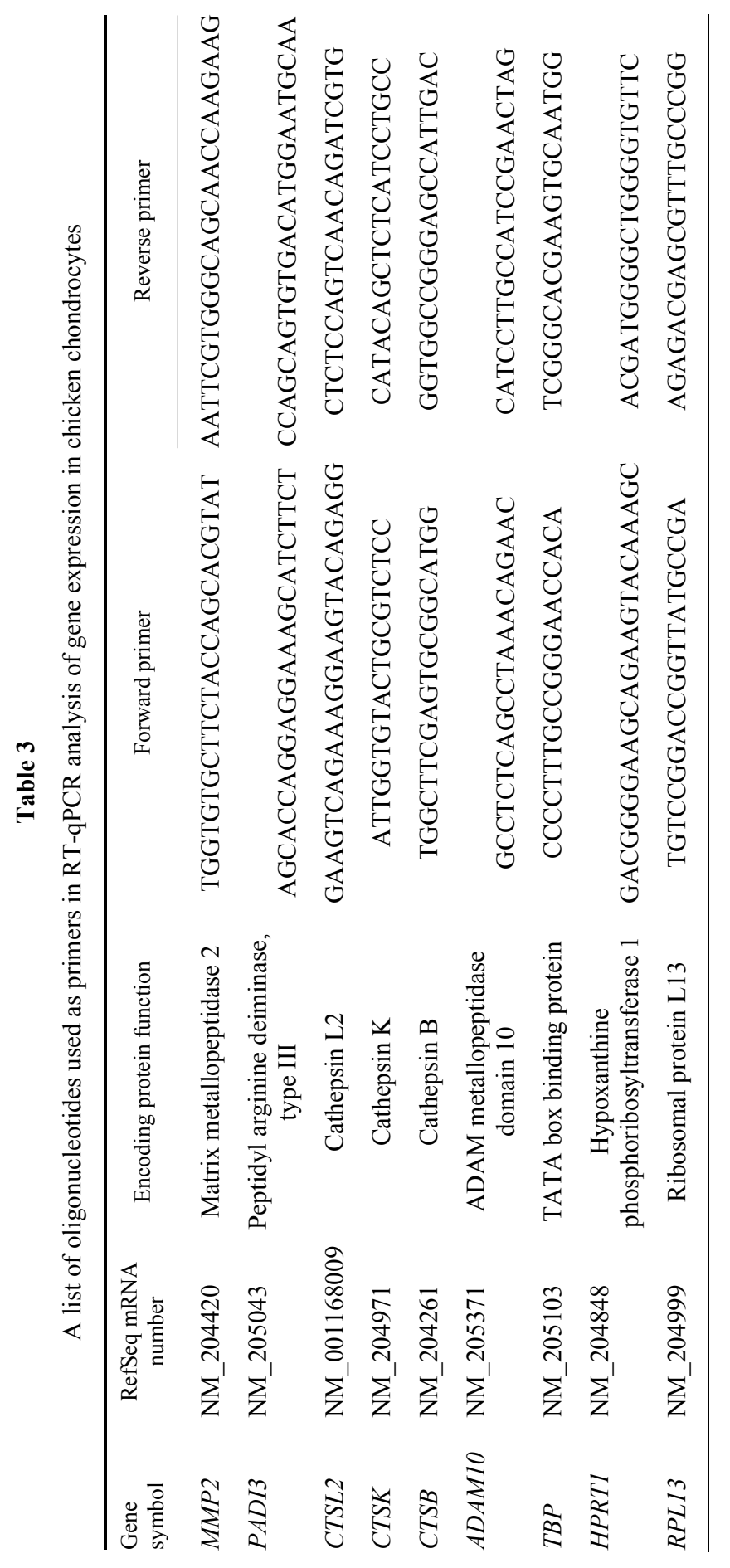



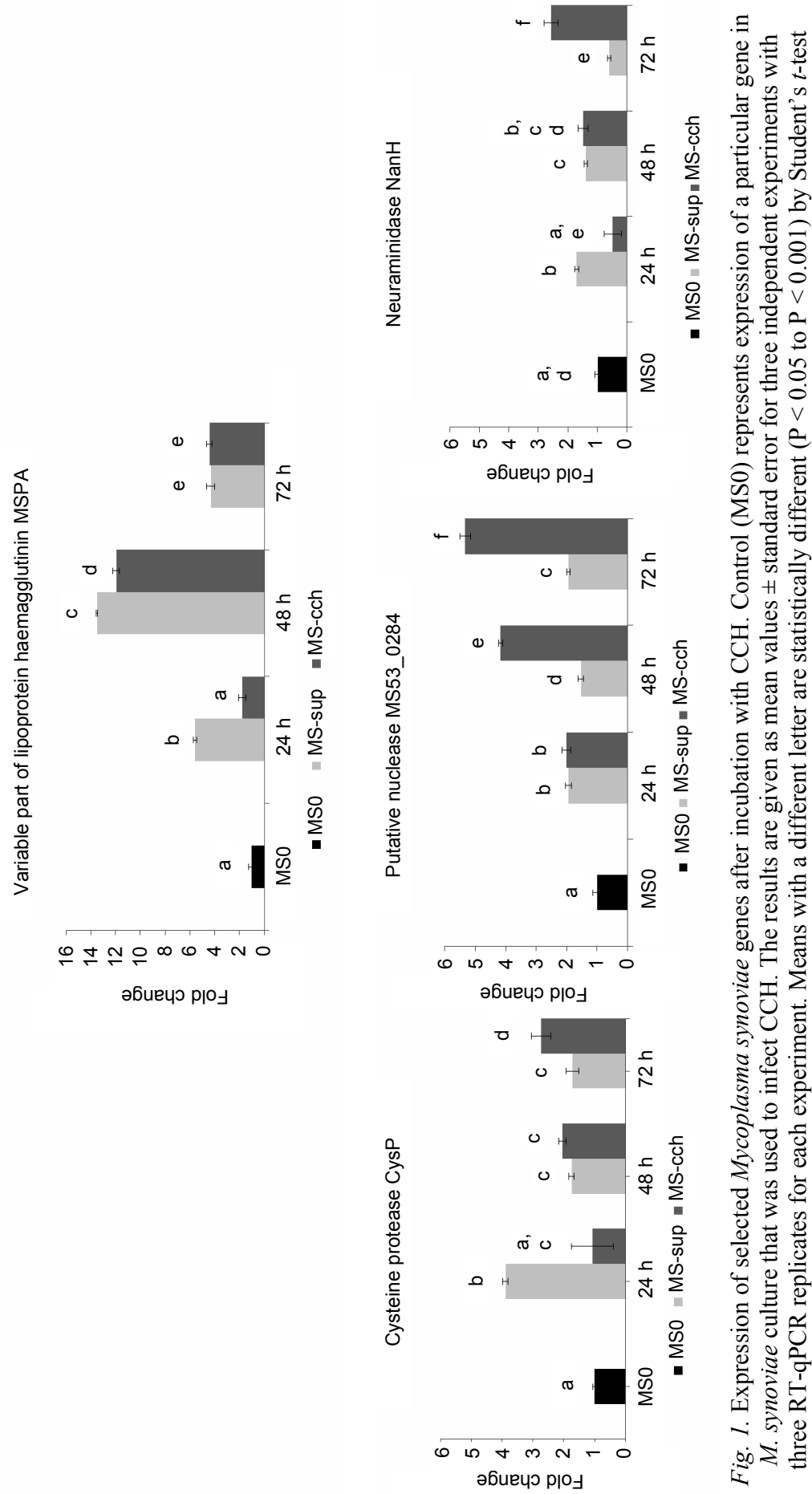
$\mathrm{P}<0.0001$ ) in expression of MSPA mRNA in M. synoviae from supernates after $24 \mathrm{~h}$ of incubation (MS-sup24), a 13.5-fold increase $(\mathrm{P}<0.0001)$ at $48 \mathrm{~h}$ post infection (PI) (MS-sup48) and a 4.3-fold increase $(\mathrm{P}<0.002)$ at $72 \mathrm{~h}$ PI (MS-sup72) compared to the M. synoviae culture used for infection of $\mathrm{CCH}$ (MS0) (Fig. 1).

The concentrations of CysP mRNA in M. synoviae cells that infected $\mathrm{CCH}$ were at the basal point at $24 \mathrm{~h}$ PI, but increased 2.7-fold during infection (MScch72, $\mathrm{P}<0.006$ ) compared to the expression in MS0. Concentrations of CysP mRNA in $M$. synoviae $\mathrm{CCH}$ supernates were significantly increased (3.9-fold, $\mathrm{P}<0.0001)$ at $24 \mathrm{~h}$ PI compared with MS0, but returned to nearly basal concentrations at $48 \mathrm{~h}$ PI $(1.7$-fold, $\mathrm{P}<0.003)$, staying at the same level at $72 \mathrm{~h}$ (Fig. 1).

The expression of MS53_0284 in M. synoviae $\mathrm{CCH}$ supernates was induced 1.9-fold at $24 \mathrm{~h}$ PI $(\mathrm{P}<0.006)$ compared that in MS0, and 2.0 -fold $(\mathrm{P}<$ 0.005 ) compared to that in infected CCH. The expression of MS53_0284 mRNA in $M$. synoviae cells collected from supernates remained at the same level also after $72 \mathrm{~h}$ PI, while in $M$. synoviae cells that infected $\mathrm{CCH}$ the expression of MS53_0284 mRNA increased after $48 \mathrm{~h}$ PI to 4.2-fold $(\mathrm{P}<0.0001)$, reaching a maximum at $72 \mathrm{~h}(5.3$-fold, $\mathrm{P}<0.0001)$ (Fig. 1).

The expression of the nan $H$ gene was highest in $M$. synoviae cells that infected $\mathrm{CCH}$ at $72 \mathrm{~h}$ PI $(2.6$-fold, $\mathrm{P}<0.004)$ and in $M$. synoviae cells from infected $\mathrm{CCH}$ supernates at $24 \mathrm{~h}$ PI $(1.7$-fold, $\mathrm{P}<0.003)$ compared to the expression in MS0. Concentrations of NanH mRNA in both types of $M$. synoviae cells were approximately 1.4-fold higher than in MS0 at $48 \mathrm{~h}$. The suppression in $n a n H$ gene expression was detected in $M$. synoviae cells that infected $\mathrm{CCH}$ at $24 \mathrm{~h}$ PI (0.5-fold) and in M. synoviae cells from infected $\mathrm{CCH}$ supernates at $72 \mathrm{~h}$ PI (0.6-fold, $\mathrm{P}<0.004)$ (Fig. 1).

Gene expression of $\mathrm{CCH}$ after infection with $\mathrm{M}$. synoviae

The expression of genes encoding several catabolic enzymes of the cartilage extracellular matrix (cathepsins B, K and L, aggrecanase ADAM10 and matrix metalloproteinase II, MMP2) were induced following $48 \mathrm{~h}$ infection of $\mathrm{CCH}$ with $M$. synoviae. Hence, the expression of MMP2 increased 3.4-fold $(\mathrm{P}<0.02)$, cathepsin L (CTSL2) 3.6-fold ( $<<0.01)$, cathepsin K (CTSK) 2.7-fold $(\mathrm{P}<0.01)$, cathepsin $\mathrm{B}(\mathrm{CTSB}) 2.1$-fold $(\mathrm{P}<0.04)$, and aggrecanase ADAM 10 (ADAM10) 6.0 -fold $(\mathrm{P}<0.01)$. Interestingly, the expression was not significantly increased in $\mathrm{CCH}$ after $24 \mathrm{~h}$ and $72 \mathrm{~h}$ infection, while expression of cathepsin B was increased approximately 2 -fold at all measurement times. In addition to genes whose encoding proteins presumably contribute to cartilage destruction, a gene encoding the enzyme peptidyl arginine deiminase III (PADI3) was analysed for changes in gene expression. Compared to the genes encoding catabolic enzymes, PADI3 showed a significantly stronger level of upregulation after $48 \mathrm{~h}$ of $\mathrm{CCH}$ infection with M. synoviae (16.7-fold, $\mathrm{P}<0.01$ ) (Fig. 2). 

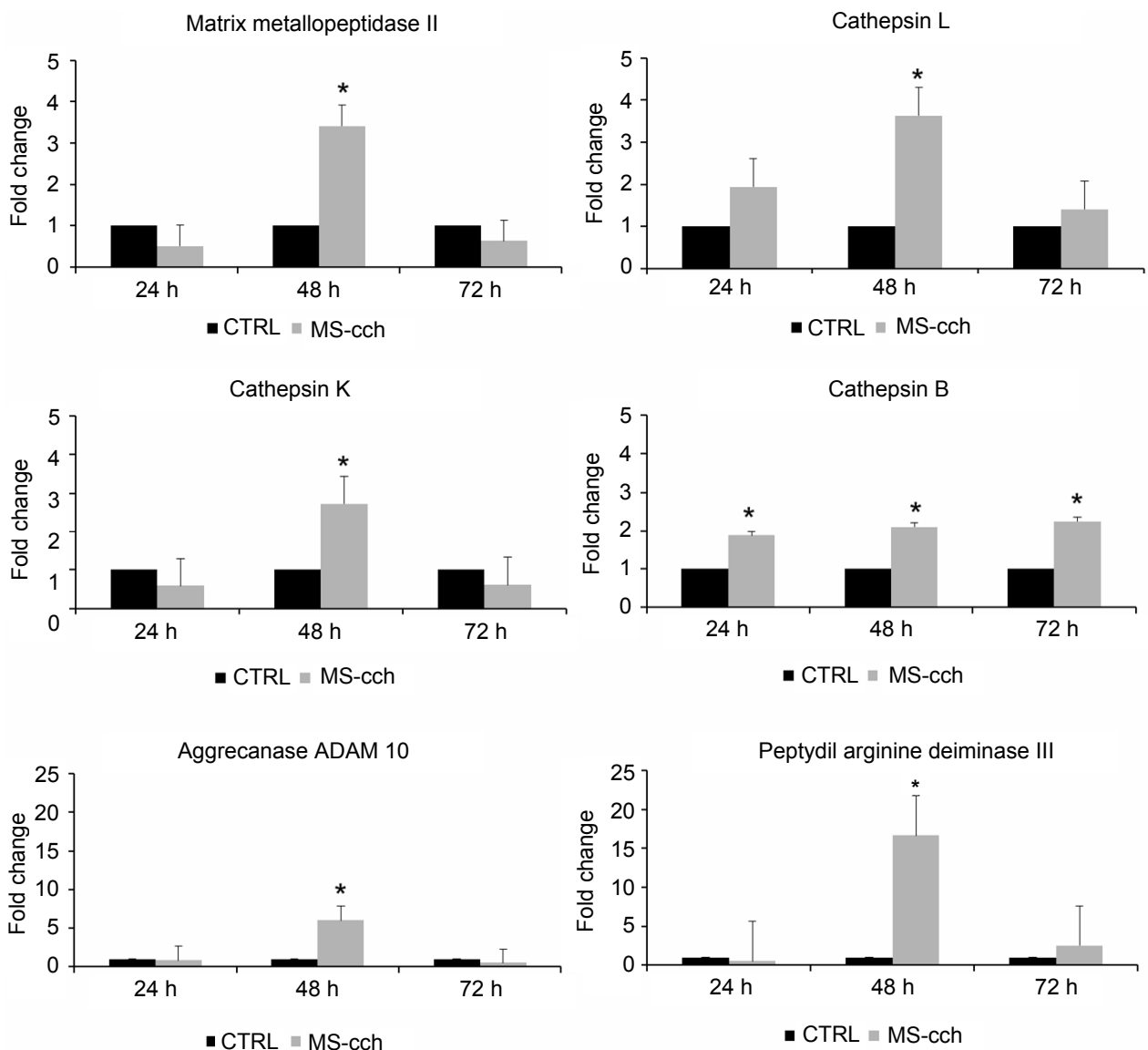

Fig. 2. Expression of selected genes in CCH after exposure to Mycoplasma synoviae WVU 1853. The control (CTRL) in all graphs represents non-exposed CCH. The results are given as mean values \pm standard error for three independent cell treatment experiments with three RT-qPCR replicates for each experiment. Means marked with stars are statistically different from controls $(\mathrm{P}<0.05$ to $\mathrm{P}<0.001)$ by Student's $t$-test

\section{Discussion}

To investigate $M$. synoviae induced by host cells, we exposed $\mathrm{CCH}$ to mycoplasma and explored the expression of several genes involved in M. synoviae pathogenicity and also genes encoding cartilage-degradation-linked enzymes in $\mathrm{CCH}$. Mycoplasmas, including M. synoviae, are associated with joint infections leading to cartilage degradation and induction of autoimmunity. In addition to enzymes for degradation of extracellular matrix, PADI3 encodes an enzyme responsible for citrullination of proteins linked to the induction of autoimmunity in human rheumatoid arthritis (Yamada, 2005; Uysal et al., 2010). 
Our previous studies found that $24 \mathrm{~h}$ after infection, $1.2 \pm 0.3 \%$ of $M$. synoviae invaded $\mathrm{CCH}$, while other $M$. synoviae cells were attached to $\mathrm{CCH}$ or remained in culture supernates (Dušanić et al., 2009). Invaded and attached bacteria are in direct contact with $\mathrm{CCH}$, the cytoplasm and surface of which can be considered as different infection environments than culture supernatants. Since all bacteria originated from a single broth culture, and RNA was isolated for all tested conditions at the same time, the expression of genes could be directly compared. Under two different environmental conditions, time-dependent trends of gene expression for CysP, NanH and MS53_0284 proceeded in opposite directions, increasing in attached or invaded $M$. synoviae and decreasing in culture supernatant $M$. synoviae. The vlhA gene of $M$. synoviae yields a product that is cleaved posttranslationally into an N-terminal lipoprotein (MSPB) and a C-terminal haemagglutinin protein (MSPA). Both MSPA and MSPB are surface-exposed proteins and exhibit high frequency antigenic variation, but only MSPA mediates binding to erythrocytes and is involved in the adhesion process (Noormohammadi et al., 1997). In our experiments for both environments the upregulation at all times with a peak at $48 \mathrm{~h}$ was observed for the gene encoding the most prominent adhesin in M. synoviae, the MSPA part of VlhA. Our results indicate that the host cell environment influences upregulation of the adhesion-associated gene in M. synoviae.

The highest gene expression of cys $P$ and $n a n H$ in bacteria present in the culture supernatant was detected at $24 \mathrm{~h}$ PI. Although there is a link between VlhA and bacterial capacity to cause infectious synovitis (Narat et al., 1998), no such correlation has been observed for CysP so far. According to our observations, M. synoviae cleaves chicken IgGs, which are also found in $\mathrm{CCH}$ growth medium (Cizelj et al., 2011). Degradation of host IgG could enable M. synoviae to escape the immune system defence. This mechanism is more effective for nonattached and non-invaded bacteria, which is supported by our results.

Neuraminidase NanH of $M$. synoviae has been found to desialylate chicken IgGs and tracheal mucus glycoproteins (Berčič et al., 2011). Desialylation is important for tissue colonisation and could explain the high level of gene expression at $24 \mathrm{~h}$ PI. Both CysP and NanH could be important for providing M. synoviae with sources of energy and other growth requirements. Therefore, upregulation of both genes in attached and invaded bacteria at $72 \mathrm{~h}$ PI could be a response to needs for such sources.

The hypothetical protein MS53_0284 of M. synoviae is noted as a staphylococcal nuclease homologue (Vasconcelos et al., 2005). Upregulation of MS53_0284 in M. synoviae attached and invaded into CCH suggests that this putative nuclease may play a role in the host's nucleic acid degradation. This result may be relevant to our previous findings on $M$. synoviae-induced apoptosis in CCH (Dušanić et al., 2012). The upregulation of MS53_0284 gene in mycoplasma cells that were in supernatants of infected $\mathrm{CCH}$ could be triggered by nucleic acids released from dead $\mathrm{CCH}$ cells. 
In addition to the possible role of bacterial proteases in the cleavage of collagens, several proteases originating from immune cells, inflamed synovium and necrotic or apoptotic $\mathrm{CCH}$ have been implicated in cartilage degradation (Bartok and Firestein, 2010). Cartilage collagens and proteoglycans are a target of MMPs, aggrecanases and cathepsins B, K and L (Goldring and Marcu, 2009). The results of our study show that in $\mathrm{CCH}$ M. synoviae infection upregulates the expression of aggrecanase, metalloproteinase and cathepsins $\mathrm{K}$ and $\mathrm{L}$ at $48 \mathrm{~h} \mathrm{PI}$, while cathepsin B gene was upregulated at all times. This indicates that $M$. synoviae may play a role in tissue degradation in infectious synovitis by inducing gene expression in $\mathrm{CCH}$. It has been reported that $M$. hyorhinis and M. arthritidis are able to cause a significant release of calcium from bone tissue (Novak et al., 1995). Increases in calcium concentration during inflammation could be a stimulus for activation of peptidyl arginine deimidase (PADI), leading to citrullination and the appearance of new epitopes for autoantibodies (Vossenaar et al., 2004). In the present study, PADI3 showed a significantly higher level of upregulation after $48 \mathrm{~h}$ of $\mathrm{CCH}$ infection with $M$. synoviae. These results could connect $M$. synoviae with the autoimmune nature of infectious synovitis.

In conclusion, the expression of genes important for the pathogenicity of $M$. synoviae is time dependent and influenced by environmental conditions. We have shown that $M$. synoviae induced the expression of genes encoding cathepsins $\mathrm{B}, \mathrm{K}$, $\mathrm{L}$ and $\mathrm{PADI} 3$ in $\mathrm{CCH}$.

\section{Acknowledgement} (ARRS)

The study was supported by grant P4-0220 from the Slovenian Research Agency

\section{References}

Bartok, B. and Firestein, G. S. (2010): Fibroblast-like synoviocytes: key effector cells in rheumatoid arthritis. Immunol. Rev. 233, 233-255.

Berčič, R. L., Cizelj, I., Dušanić, D., Narat, M., Zorman-Rojs, O., Dovč, P. and Benčina, D. (2011): Neuraminidase of Mycoplasma synoviae desialylates heavy chain of the chicken immunoglobulin G and glycoproteins of chicken tracheal mucus. Avian Pathol. 40, 299-308.

Cecchini, K. R., Gorton, T. S. and Geary, S. J. (2007): Transcriptional responses of Mycoplasma gallisepticum strain R in association with eukaryotic cells. J. Bacteriol. 189, 5803-5807.

Cizelj, I., Berčič, R. L., Dušanić, D., Narat, M., Kos, J., Dovč, P. and Benčina, D. (2011): Mycoplasma gallisepticum and Mycoplasma synoviae express a cysteine protease CysP, which can cleave chicken IgG into Fab and Fc. Microbiology 157, 362-372.

Dušanić, D., Benčina, D., Oven, I., Cizelj, I., Benčina, M. and Narat, M. (2012): Mycoplasma synoviae induces upregulation of apoptotic genes, secretion of nitric oxide and appearance of an apoptotic phenotype in infected chicken chondrocytes. Vet. Res. 43, 7.

Dušanić, D., Berčič, R. L., Cizelj, I., Salmič, S., Narat, M. and Benčina, D. (2009): Mycoplasma synoviae invades non-phagocytic chicken cells in vitro. Vet. Microbiol. 138, 114-119.

Goldring, M. B. and Marcu, K. B. (2009): Cartilage homeostasis in health and rheumatic diseases. Arthritis Res. Ther. 11, 224. 
Hallamaa, K. M., Tang, S. L., Ficorilli, N. and Browning, G. F. (2008): Differential expression of lipoprotein genes in Mycoplasma pneumoniae after contact with human lung epithelial cells, and under oxidative and acidic stress. BMC Microbiol. 8, 124.

Kerr, K. M. and Olson, N. O. (1970): Pathology of chickens inoculated experimentally or contactinfected with Mycoplasma synoviae. Avian Dis. 14, 290-320.

Lockaby, S. B., Hoerr, F. J., Lauerman, L. H. and Kleven, S. H. (1998): Pathogenicity of Mycoplasma synoviae in broiler chickens. Vet. Pathol. 35, 178-190.

Morrow, C. J., Whithear, K. G. and Kleven, S. H. (1990): Restriction endonuclease analysis of Mycoplasma synoviae strains. Avian Dis. 34, 611-616.

Narat, M., Benčina, D., Kleven, S. H. and Habe, F. (1998): The hemagglutination-positive phenotype of Mycoplasma synoviae induces experimental infectious synovitis in chickens more frequently than does the hemagglutination-negative phenotype. Infect. Immun. 66, 6004-6009.

Noormohammadi, A. H., Markham, P. F., Whithear, K. G., Walker, I. D., Gurevich, V. A., Ley, D. H. and Browning, G. F. (1997): Mycoplasma synoviae has two distinct phase-variable major membrane antigens, one of which is a putative hemagglutinin. Infect. Immun. 65, 2542-2547.

Novak, J. F., Hayes, J. D. and McMaster, J. H. (1995): Mycoplasma-mediated bone resorption in bone organ cultures. Microbios 81, 241-260.

Pfaffl, M. W. (2001): A new mathematical model for relative quantification in real-time RT-PCR. Nucleic Acids Res. 29, e45.

Razin, S., Yogev, D. and Naot, Y. (1998): Molecular biology and pathogenicity of mycoplasmas. Microbiol. Mol. Biol. Rev. 62, 1094-1156.

Rodwell, A. W. and Whitcomb, R. F. (1983): Methods for direct and indirect measurement of mycoplasma growth. In: Tully, J. G. and Razin, S. (eds) Methods in Mycoplasmology. Academic Press, New York-London. pp. 185-196.

Uysal, H., Nandakumar, K. S., Kessel, C., Haag, S., Carlsen, S., Burkhardt, H. and Holmdahl, R. (2010): Antibodies to citrullinated proteins: molecular interactions and arthritogenicity. Immunol. Rev. 233, 9-33.

Vasconcelos, A. T., Ferreira, H. B., Bizarro, C. V., Bonatto, S. L., Carvalho, M. O., Pinto, P. M., Almeida, D. F., Almeida, L. G., Almeida, R., Alves-Filho, L., Assuncao, E. N., Azevedo, V. A., Bogo, M. R., Brigido, M. M., Brocchi, M., Burity, H. A., Camargo, A. A., Camargo, S. S., Carepo, M. S., Carraro, D. M., de Mattos Cascardo, J. C., Castro, L. A., Cavalcanti, G., Chemale, G., Collevatti, R. G., Cunha, C. W., Dallagiovanna, B., Dambros, B. P., Dellagostin, O. A., Falcao, C., Fantinatti-Garboggini, F., Felipe, M. S., Fiorentin, L., Franco, G. R., Freitas, N. S., Frias, D., Grangeiro, T. B., Grisard, E. C., Guimaraes, C. T., Hungria, M., Jardim, S. N., Krieger, M. A., Laurino, J. P., Lima, L. F., Lopes, M. I., Loreto, E. L., Madeira, H. M., Manfio, G. P., Maranhao, A. Q., Martinkovics, C. T., Medeiros, S. R., Moreira, M. A., Neiva, M., Ramalho-Neto, C. E., Nicolas, M. F., Oliveira, S. C., Paixao, R. F., Pedrosa, F. O., Pena, S. D., Pereira, M., Pereira-Ferrari, L., Piffer, I., Pinto, L. S., Potrich, D. P., Salim, A. C., Santos, F. R., Schmitt, R., Schneider, M. P., Schrank, A., Schrank, I. S., Schuck, A. F., Seuanez, H. N., Silva, D. W., Silva, R., Silva, S. C., Soares, C. M., Souza, K. R., Souza, R. C., Staats, C. C., Steffens, M. B., Teixeira, S. M., Urmenyi, T. P., Vainstein, M. H., Zuccherato, L. W., Simpson, A. J. and Zaha, A. (2005): Swine and poultry pathogens: the complete genome sequences of two strains of Mycoplasma hyopneumoniae and a strain of Mycoplasma synoviae. J. Bacteriol. 187, 5568-5577.

Vossenaar, E. R., Radstake, T. R., van der Heijden, A., van Mansum, M. A., Dieteren, C., de Rooij, D. J., Barrera, P., Zendman, A. J. and van Venrooij, W. J. (2004): Expression and activity of citrullinating peptidylarginine deiminase enzymes in monocytes and macrophages. Ann. Rheum. Dis. 63, 373-381.

Yamada, R. (2005): Peptidylarginine deiminase type 4, anticitrullinated peptide antibodies, and rheumatoid arthritis. Autoimmun. Rev. 4, 201-206. 